\title{
Research on Protection and Renewal of Traditional Ethnic Minority Areas in Xinjiang
}

\section{Dan Jiang}

Xinjiang Normal University, Urumqi, Xinjiang, China

\begin{abstract}
Historical and cultural area is an important part of urban settlement heritage space, and also an important carrier to inherit regional culture and rebrand the vitality of the old city. Based on the special regional tradition and religious culture of Xinjiang minority, and considering the problems such as the conflict between protection and renewal commonly encountered in the process of large-scale urbanization in recent years, this paper puts forward organic renewal approaches for historical and cultural areas, which is of great significance to the urban planning and development of western ethnic minority areas.
\end{abstract}

Key words: regional culture; ethnic minorities; historical and cultural areas; protection and renewal

\section{Introduction}

Historical and cultural area is defined as an urban area with a certain number and scale of material relics (such as historical buildings and cultural relics) and non-material relics (such as human settlement culture and folk customs). It is still a human settlement heritage space that can truly reflect the traditional settlement pattern. In the vast and vigorous land of Xinjiang, up to now, there are many historical and cultural areas of ethnic minority. They were born under the influence of primitive natural ecological conditions and traditional cognitive ability. In the evolution process of human-land relationship with oasis as the basic living place in all dynasties, they have always retained local and simple human settlement values and are an important part of the human settlement social structure in western China.

In recent years, projects such as planning and reconstructing Xinjiang's old city and commercial development have made remarkable achievements. However, due to the special religious environment and other problems in ethnic areas, the large-scale transformation of historical and cultural areas has had a great impact on the changes in the spatial pattern of primitive human settlements and social relations, resulting in a series of problems, such as excessive capitalization, demolition and reconstruction of residential buildings, imitation and collage of cultural values, etc. Therefore, this paper tries to consider the renewal of historical and cultural areas and the transformation of social relations in the process of urban design, combining the theoretical perspective of regional cultural pattern, so as to enrich the ways of protection and renewal of historical and cultural areas of ethnic minorities in Xinjiang.

\section{The Understanding of Regional Culture}

Culture creates society, while soil and water breeds culture. Regional culture refers to the distinctive human culture created in a specific region, which plays an important role in maintaining the locality of human settlement environment. It

Copyright $(2020$ by author(s) and Frontier Scientific Research Publishing Inc.

This work is licensed under the Creative Commons Attribution International License (CC BY 4.0).

http://creativecommons.org/licenses/by/4.0/ 
is an integral part of regional economic and social development that cannot be ignored.

\subsection{Natural environment}

Natural environment is the geographical relationship established between human beings and their living environment, which includes the influence of natural factors such as soil and water, climate, topography and geomorphology on human life under a certain level of social productivity, as well as human cognition and grasp of the living environment. As the material support of the historical and cultural areas, natural environment has created the characteristics of the formation of human settlement pattern, and has become an important factor restricting the development of the man-land relationship in the historical stage of underdeveloped productivity. It has played a rigid role in restricting the formation and rise and fall of the historical and cultural areas.

\subsection{Religious thought}

Religious thought is the historical product of human settlement behavior on the basis of certain social norms. Rooted in the deep regional traditional ethical culture, accompanied by the evolution and development of historical and cultural areas in ethnic minority areas, it covers a large number of experience and rules of settlement. As a kind of social ideology, it is the basic generalization of the relationship between people and people, people and society, and people and nature. It is the spiritual carrier to construct the sense of identity and belonging of places, and it profoundly affects the morphological characteristics of historical and cultural areas.

\subsection{Human settlement forms}

With its unique regional characteristics, Xinjiang minority areas bear complex composition of social relations, which have become a microcosm of the process of urban change. The human settlement forms in the historical and cultural areas is the most subtle and meticulous material embodiment of the regional characteristics. Connecting human behavior with economy, politics, customs and religious systems, it is not only a spiritual space for the psychological state and lifestyle of ethnic minorities, but also a manifestation of regional human settlements and ethical relations. In addition, it also presents multiple and composite human settlements cultural characteristics.

\section{Organic Renewal of Ethnic Minority Historical and Cultural Areas under Regional Culture}

Since the beginning of this century, the large-scale organic renewal projects in the historical and cultural areas of the ethnic minority areas in Xinjiang have been increasing year by year, and the project tasks have also become more comprehensive and multi-objective. However, it is not difficult to find that there are a large number of phenomena behind some completed project cases that run counter to the rules of regional culture. They blindly use nationality as a reflection to resist the diversity of the times, and even use "nationality" and "region" as excuses to cater to interests. These are not only the loss of regional culture, but also the denial of the spirit of the times.

Therefore, on the basis of further sorting out the space and social relations of Xinjiang minority historical and cultural areas, starting from the social functions and social logical roots of the buildings, building groups and various blocks in the historical and cultural areas, and aiming at the special regional tradition and religious ethical background of ethnic minorities, this paper will put forward organic renewal strategies.

3.1 To enhance the radiation intensity of material historical and cultural space

In view of the historic ethnic buildings, mosques and cultural relic protection units in the historical and cultural areas, efforts should be intensified to protect cultural relics. It should be moderately developed in the way of repairing the old as before, and it should be shaped into a "facade space" with urban control by landscape design methods. At the same time, new landscape nodes and greening systems should be added according to the spatial characteristics, municipal facilities with historical features should be added, and the radiation range of landmark space nodes should be further enhanced. 
3.2 To drive the natural transition between primitive settlement space and commercial space

In view of the business district, compulsory reconstruction can be carried out on the basis of the original buildings and street facades in combination with style and features. For example, the commercial and residential mode such as "the front is shop and the back is house, the ground floor is shop and the above is house" should be retained. In addition, the public tourist areas and traditional residential areas should be strictly divided through the way of street planning and reconstruction to promote the natural transition between the primitive residential space and the new commercial space, so as to carry forward the traditional folk culture of Xinjiang's ethnic minorities and promote the development of the tourismaffiliated economic industry chain.

\subsection{To protect and continue primitive social relations}

In view of the areas inhabited by aborigines, the mode of combining protection with renovation should be adopted. For example, the old and dilapidated residential buildings are replaced by the new by the "insertion method", the street scale of the main street space is widened, and reasonable planning is adopted to reduce the number of residential openings along the entrance roadway. In addition, it is an important way to continue the primitive social relations in the historical and cultural areas of ethnic minorities to formulate effective resettlement measures and strictly control the small emigration rate and the large return rate after renovation, so as to reduce the degree of dissolution of the social pattern of the aborigines.

\section{Conclusions}

Historical and cultural area is an important part of urban heritage space, and it is also an important carrier to rebrand the vitality of the old city and inherit the regional culture. The research conducted in this paper is only an attempt to explore the road of urban design, aiming to explore a more reasonable way to protect and renew the historical and cultural areas of ethnic minorities.

\section{Conflicts of Interest}

The author declares no conflicts of interest regarding the publication of this paper.

\section{Acknowledgments}

Research on Cultural Landscape Heritage Corridor of Xinjiang Section of Silk Road (Project Number: XJEDU2017RS048).

\section{References}

[1] Christian N.S. and Genius L. (2010). Towards a Phenomenology of Architecture. Huazhong University of Science and Technology Press, Hubei, 125.

[2] Georgia B.W. and Ian B. (2010). Design and Place Identity. China Construction Industry Press, Beijing, 228.

[3] Zhang Y.G. (2012). Interpretation and Expression of Place Spirit in Contemporary Context. Tsinghua University, Beijing, 36 .

[4] Li Q. (2014). On the Coupling of Settlement Space in Kashgar Ancient City, Journal of Nanjing University of the Arts (Art and Design Edition). (4): 104-108.

[5] Zhou K., Yan K. and Wang J. (2015). Re-interpretation of the Place Spirit: Also on the Protection and Reuse of Architectural Heritage. Journal of Sichuan Normal University (Social Science Edition), (3): 67-72. 